\title{
ROTAS DA INTERNACIONALIZAÇÃO ACADÊMICA: CASO EAESP/FGV
}

\section{RESUMO}

Este trabalho tem por objetivo analisar aspectos teóricos e práticos do processo de internacionalização acadêmica da EAESP/FGV, por meio dos principais eventos e caminhos desenvolvidos ao longo de seus 60 anos de existência. Foram realizadas duas pesquisas empíricas, envolvendo ex-diretores, coordenadores dos principais programas internacionais, bem como todos os professores da Escola sobre suas formações e atividades internacionais. Concluiu-se que a EAESP/FGV tem desenvolvido uma trajetória internacional diversificada e consolidada, ultrapassando as atividades relacionadas com mobilidade docente e discente. Mas, existem algumas limitações para aprofundamento da internacionalização como marca estratégica da instituição. Ao fim, a contribuição deste trabalho está em indicar como as práticas de internacionalização adotadas pela EAESP/FGV, refletem a realidade de época de suas estratégias internacionais que sustentam, atualmente, a sua posição competitiva junto às escolas de negócios globais.

Palavras-chaves: Educação Superior; Internacionalização da Educação Superior; Estratégia de Internacionalização Acadêmica; Inserção Internacional.

\section{ROUTES OF ACADEMIC INTERNATIONALIZATION: CASE EAESP/FGV}

\begin{abstract}
This work has as its main objective analyzes the theoretical and practical aspects of academic internationalization process, through the main events and pathways developed over the 60 years of the EAESP/FGV - São Paulo Business School of the Getulio Vargas Foundation. Two empirical surveys were conducted, involving former directors, coordinators of the major international programs, and all professors who teach at the institution about their formation and international activities. It was concluded that the EAESP/FGV has developed an international, diversified and consolidated trajectory, surpassing the activities related to professor and student mobility. However, some limitations have been identified for further development of internationalization as a strategic brand of the institution. At the end, the contribution of this work is to indicate how the internationalization practices adopted by EAESP / FGV, reflect the reality of the time of their international strategies that support currently its competitive position within the global business schools.
\end{abstract}

Keywords: Higher Education; Internalitionalization of Higher Education; Strategy of Academic Internationalization; International Insertion. 


\section{VÍAS DE INTERNACIONALIZACIÓN ACADÉMICA: EAESP CASO / FGV}

\section{RESUMEN}

Este trabajo tiene como objetivo analizar los aspectos teóricos y prácticos de la internacionalización académica de EAESP / FGV, a través de los principales acontecimientos y las vías de desarrollado a lo largo de sus 60 años de existencia. Se llevaron a cabo dos estudios empíricos, que involucra al ex directores, coordinadores de los principales programas internacionales, así como todos los maestros de la escuela sobre su formación y actividades internacionales. Se concluyó que la EAESP / FGV ha desarrollado una carrera internacional diversa y consolidada, superando las actividades relacionadas con la enseñanza y la movilidad de los estudiantes. Sin embargo, hay algunas limitaciones para profundizar la internacionalización como una marca estratégica de la institución. Al final, la contribución de este trabajo es indicar cómo las prácticas de internacionalización adoptadas por EAESP / FGV, reflejan la realidad de la época de sus estrategias internacionales que apoyan actualmente su posición competitiva dentro de las escuelas de negocios a nivel mundial.

Palabras clave: Educación Superior; La Internacionalización de la Educación Superior; Estrategia de Internacionalización Académica; Integración Internacional.

\footnotetext{
${ }^{1}$ Doutora em Administração de Empresas pela Escola de Administração de Empresas de São Paulo da Fundação Getulio Vargas - EAESP/FGV. Professora da Escola de Administração de Empresas de São Paulo da Fundação Getulio Vargas - EAESP/FGV. Brasil. E-mail: ester.freitas@fgv.br

${ }^{2}$ Doutor em Doutorado Ph D pela Cornell University, Estados Unidos. Professor da Escola de Administração de Empresas de São Paulo da Fundação Getulio Vargas - EAESP/FGV. Brasil. E-mail: carlos.bertero@fgv.br

${ }^{3}$ Doutora em Sociologia pela Universidade de São Paulo - USP. Professora da Escola de Administração de Empresas de São Paulo da Fundação Getulio Vargas - EAESP/FGV. Brasil. E-mail: mtereza.fleury@fgv.br

4 Doutor em Adminisração de Empresas pela Stanford University, Estados Unidos. Professor da Escola de Administração de Empresas de São Paulo da Fundação Getulio Vargas - EAESP/FGV. Brasil. E-mail: fabio.mariotto@fgv.br

${ }^{5}$ Doutor em Administração de Empresas pela Escola de Administração de Empresas de São Paulo da Fundação Getulio Vargas - EAESP/FGV. Professor da Escola de Administração de Empresas de São Paulo da Fundação Getulio Vargas EAESP/FGV. Brasil. E-mail: andre.luis.silva @ fgv.br
} 


\section{INTRODUÇÃO}

As sociedades contemporâneas são afetadas pela combinação e interdependência das exigências de sua economia doméstica, as da expansão do comércio internacional e as derivadas do crescimento da regionalização econômica, como a União Europeia, NAFTA, ASEN, APEC, MERCOSUL, dentre outras. A elevação do volume de investimentos internacionais, a multiplicação de processos de fusão e aquisição de empresas de diversos setores, a integração global de processos produtivos, tecnológicos, informacionais e financeiros, que aceleram os níveis de competição e de inovação, têm gerado fortes impactos no mercado mundial de trabalho qualificado, influenciando diretamente os sistemas de ensino e pesquisa dos países. Estes são pressionados a darem respostas rápidas e de qualidade em um mundo complexo e em transformação permanente. Neste cenário, o capital intelectual das nações assume características de fator estratégico.

O capital intelectual é um ativo social que determina e aprofunda as assimetrias entre as sociedades, organizações e grupos (Stewart, 1998; Stiglitz, 2003; 2006). Ele é um diferencial entre nações, que fazem escolhas sobre investimentos na área de educação, decide qual é a importância da educação nas suas prioridades e o lugar pretendido no mundo das ciências e das tecnologias, cujo papel é inegável em uma economia cada vez mais globalizada. As instituições que formam este sistema têm graus diferentes de autonomia, a depender das políticas de governo para gerir este capital, aprimorando-o ou estagnando-o. O capital intelectual é o estoque de conhecimentos, informações, propriedade intelectual e experiências que pode ser usado por um país ou organização para gerar e gerir a sua riqueza (Stewart, 1998), portanto, quanto mais este capital for nutrido, apoiado e estimulado, mais o país ou organização terá vantagens em relação aos seus competidores e maior autonomia para influenciar o futuro que deseja. É neste contexto que entendemos a importância do debate sobre internacionalização das instituições de ensino superior, uma vez que elas são uma das mais significativas fontes de formação e aperfeiçoamento do capital intelectual, responsáveis pela qualificação de profissionais que atuarão na busca de respostas que contemplem o desenvolvimento interno de seus países e a sua maior participação na economia mundial.

A literatura sobre internacionalização acadêmica ou das instituições de ensino superior é vasta, traz a problemática da definição (Knight, 1994; Jang, 2009; Warwick, 2014) e enfatiza a necessidade de se diferenciar internacionalização de globalização. Escolhemos alguns autores mais citados neste debate e percebemos que existe uma grande consistência na maneira como entendem estes termos, ou seja, para eles tratam-se de processos, portanto fenômenos que estão sempre em mudanças, aperfeiçoamentos e aprofundamentos. Assim, apenas é possível considerar internacionalização ou globalização como dinâmicas, desenvolvimentos e evoluções.

Knight (2003) compreende a internacionalização das instituições de ensino superior como um processo produzido por um conjunto de políticas e práticas definidas no nível nacional, setorial e institucional que integra uma dimensão internacional, intercultural ou global nos objetivos, funções ou produtos da educação pós-secundária. Por outro lado, a globalização se configura como um esforço contínuo, que denota desenvolvimento ou evolução de fluxos econômicos, tecnológicos, de conhecimentos, de pessoas, de valores e de ideias sem fronteiras. Trata-se de um fenômeno multifacetado, que apresenta oportunidades, desafios e riscos. Segundo ele, a internacionalização está mudando o mundo da educação e a globalização está mudando o mundo da internacionalização.

Van der Wende (2001) também considera que a internacionalização das instituições de ensino superior é uma resposta à globalização, senda esta um processo externo aos países, de caráter macrossocial, sobre as convergências e interdependências de mercados competitivos. Para o autor, a internacionalização apresenta simultaneamente uma face cooperativa e outra competitiva. A internacionalização é, pois, uma dimensão nas políticas educacionais, definidas no nível nacional ou institucional para fazer face aos desafios globais. Em Warwick (2014) a defesa de ambos os fenômenos como processos interno e externo também é clara, pois a internacionalização é vista como respostas à globalização do ambiente operacional das instituições e a globalização como uma externalidade que pressiona e catalisa as mudanças dos sistemas de ensino e pesquisa. Ainda, Bennel e Pearce (2003) detalham a globalização enquanto processo complexo, que envolve desregulamentação de mercados, gera uma demanda maciça pelo reconhecimento acadêmico, provoca a transnacionalização do management e desenvolve uma comunidade global de negócios baseada em uma cultura mais uniforme, com práticas e linguagem que incentivam a aquisição de competências e habilidades requeridas pelo modelo corporativo. Segundo estes autores, as corporações transnacionais e os investidores estrangeiros buscam se assegurar de que os seus empregados espalhados pelo mundo partilham o mesmo conjunto de habilidades, que garantem um padrão de qualidade uniforme para melhor aproveitamento das oportunidades existentes em um mercado global.

Percebemos nestes autores uma congruência entre os processos internacionalização e globalização, que se influenciam mutuamente e elevam o nível competição entre as instituições, como atestam os rankings internacionais. Dentre os mais consultados, o ARWU (Academy Ranking of World Universities) desenvolvido pela Universidade Jiao Tong, em Xangai, 
classifica as 500 melhores universidades do mundo a partir de seis indicadores que incluem o número de exalunos que detém Premio Nobel e a Medalha Field (Matemática). Mais abrangente que o ARWU, o londrino Times Higher Education envolve avaliação de instituições em 144 países e conta com a participação de 16 mil profissionais convidados para operar o sistema de avaliação, cujo teor é classificado em cinco categorias: ensino, pesquisa, citações, presença internacional e inovação; os indicadores do Financial Times classificam a posição profissional de ex-alunos de cursos de MBA e os salários percebidos após a conclusão do curso.

A conquista de posições superiores nestes rankings significa a elevação do prestígio institucional internacional, valorização no mercado global dos títulos assinados por estas instituições e exerce uma enorme atração em um contingente crescente de jovens que cada vez mais pensam o mundo como a sua casa. Dados recentes apresentados no relatório da OCDE (OCDE, 2014) estimam em 4,5 milhões de estudantes fora de seu país de origem, sendo que $82 \%$ de todos esses estrangeiros estão matriculados em países do G20 (75\% deles nos países membros da OCDE). Trata-se evidentemente de um mercado importante que traz benefícios para as economias locais, para as instituições que recebem estes alunos, para os países de origem destes estrangeiros, caso retornem, para as organizações que os contratam e para os indivíduos que aproveitam as oportunidades destinadas aos que têm uma sólida formação profissional. Os dados da OCDE testemunham a validação de um novo tipo de capital simbólico associado ao conteúdo acadêmico, a mobilidade (Allemand, 2004; Freitas, 2005; 2008; 2009), que permite os encontros interculturais e o desenvolvimento de uma mentalidade em que as convivências com portadores de diferentes culturas são assimiladas naturalmente, caracterizando um diferencial no mercado de trabalho altamente qualificado, diverso e global.

Considerada uma das escolas de negócios mais reputadas do Brasil, a Escola de Administração de Empresas da Fundação Getúlio Vargas (EAESP/FGV), foi escolhida para ter o seu processo de internacionalização analisado neste artigo, em virtude de ser uma instituição ímpar, que tem a sua criação e história intrinsecamente ligada ao processo de internacionalização de uma universidade norteamericana, a Michigan State University, portanto ela nasce com uma cultura organizacional norte-americana. Ao longo de seus 60 anos, a EAESP buscou se inserir internacionalmente.

Neste trabalho, analisamos os aspectos teóricos e práticos do processo de internacionalização acadêmica da EAESP/FGV - Escola de Administração de Empresas de São Paulo da Fundação Getúlio Vargas. A pergunta que norteia esta pesquisa é: "Quais foram as decisões e ações que a EAESP/FGV tomou durante o seu processo de internacionalização?". Para responder à esta questão, foram entrevistados os membros da diretoria que assumiram no período de 1979 a 2015 e todos os coordenadores da área de relações internacionais. Complementamos o nosso estudo com a aplicação de um questionário sobre a formação, capacitação ou participação internacional do corpo docente da EAESP. Por meio desse aporte empírico de dados, atingimos objetivo central deste trabalho: analisar aspectos teóricos e práticos do processo de internacionalização acadêmica da EAESP/FGV, por meio dos principais eventos e caminhos desenvolvidos ao longo de seus 60 anos de existência. Os desdobramentos, achados e resultados da pesquisa são esclarecidos a seguir.

\section{O AMBIENTE E AS MUDANÇAS AO LONGO DOS ANOS}

Nos Estudos Organizacionais dos anos 1960, a Teoria da Contingência, se apropriando da Teoria dos Sistemas, derrubou a separação entre fronteiras internas e externas da organização, exibindo as exigências que o ambiente lhes impõe para sobrevivência (Motta \& Vasconcelos, 2002). Analisando as variáveis ambiente, tecnologia e estrutura organizacional, Burns e Stalker (1961) determinaram que os sistemas orgânicos são os mais adequados aos mercados instáveis e incertos, em que mudanças constantes ocorrem tanto na tecnologia quando na concorrência. Estas condições exigem desses sistemas ajustes contínuos, a institucionalização da mudança como um elemento natural, a valorização das expertises e a autonomia controlada do pessoal em gestão descentralizada, mas interativa. Eles ainda apresentam elevado grau de envolvimento e compromisso com os fins organizacionais.

Alguns anos após esta teorização, Weick (1976), analisando as instituições educacionais, como local de coordenação de equipes, mecanismos de integração de papéis múltiplos, gestão descentralizada, autonomia e sentimento comum á ação, classificou-as de "loosely coupled systems". Vistas sob esta perspectiva, as instituições educacionais preservariam a identidade e a representação dos grupos heterogêneos, existiriam múltiplas lógicas de ação e racionalidades, poucos controles burocráticos e autonomia controlada nas decisões dos agentes. Assim, a aprendizagem organizacional derivada da diversidade cultural de suas partes, com diferentes visões de mundo e valores, poderia gerar soluções mais complexas e alternativas de decisão mais inovadoras neste novo contexto.

Passados 40 anos destas formulações, elas parecem cada vez mais apropriadas para analisarmos o cenário educacional mundial, particularmente o de nível superior, constituído claramente como um mercado altamente disputado e com grandes perspectivas de expansão. A educação, regulamentada pela OMC como um serviço e não um bem público (Morosini, 2011) é um segmento mundial em franca competição, na qual o prestígio da instituição em que se estudará é um trunfo inestimável. Assim, os países 
do primeiro mundo estão atentos a toda e qualquer oportunidade de novos mercados neste novo setor econômico. Como nos lembrou Van Der Wende (1999), internacionalização significa cooperação e competição.

Podemos afirmar que, se do ponto do vista do indivíduo, aluno ou "cliente", ter mobilidade é hoje um capital simbólico (Freitas, 2005, 2009), podemos também afirmar que para as instituições de ensino a sua reputação se configura como um ativo, um capital não apenas simbólico, mas com valor de mercado crescente. Os dados da OCDE (2014) confirmam estas assertivas, que são corroboradas pela Academic Reputation Survey, realizada pelo Thomson Reuters (2014), em 128 países, com objetivo de classificar a opinião dos acadêmicos a respeito da reputação de pesquisa e ensino de instituições acadêmicas globais. Também o ranking Best Global Universities envolve 750 instituições em 57 países de forma que elas possam ser comparadas globalmente. A metodologia deste ranking considera vários critérios responsáveis pela reputação das instituições, dentre eles a própria reputação global em pesquisa e a reputação em pesquisa regional. Observamos que não apenas as instituições de ensino competem por reputação, como também os diferentes institutos de rankings e de indicadores se defrontam com uma forte concorrência no setor.

$\mathrm{Na}$ literatura consultada não encontramos maiores discussões sobre os investimentos ou os custos envolvidos em um processo de internacionalização, no entanto supomos que as ações necessárias à inserção e sua manutenção são lentas e caras. As razões para esse entendimento são melhor trabalhados na seção a seguir, onde fundamentamos a literatura pertinente sobre a temática da internacionalização acadêmica.

\section{INTERNACIONALIZAÇÃO ACADÊMICA}

A literatura sobre internacionalização de empresas serve como um pano de fundo para a discussão da internacionalização acadêmica no que se refere à ideia de processo, resultante do conhecimento experiencial e da ampliação gradativa das atividades, como defendido pela Escola de Uppsala (Mariotto, 2007), porém esta expansão e crescimento implicam em ultrapassagem de níveis para se atingir um patamar mais elevado. Assim, empresas domésticas ou multidomésticas se tornam internacionais, multinacionais, globais ou transnacionais, a depender das estratégias de entrada nos novos mercados e do modelo organizacional que escolhem, particularmente no que se refere à questão do controle e governança (Adler, 2002; Pierre, 2013; Chanlat, Davel \& Dupuis, 2013; Mariotto, 2007; Madeira \& Silveira, 2013).

$\mathrm{O}$ que se percebe no caso da internacionalização de instituições de ensino é que não existe, a rigor, esta ultrapassagem, mas a combinação de políticas, práticas e atividades com foco internacional com outras que são localmente apropriadas. Ou seja, não existem instituições totalmente internacionalizadas e sem conexão com a realidade local, seja no contexto macro dos processos de internacionalização de empresas, seja no âmbito da discussão sobre a internacionalização de instituições acadêmicas.

A internacionalização das universidades não é um fenômeno novo, ainda que este tenha sido um fenômeno impulsionado pela globalização e seus desdobramentos de natureza econômica, política, social, cultural e científico-tecnológico (Reddy, 2008; Fleury, 2009). Remonta à Idade Média a criação de escolas europeias (universitas), cujos professores e alunos eram oriundos de outras regiões ou países, portanto, era predominante a presença de estrangeiros. Em períodos recentes, podemos dizer que a $2^{\mathrm{a}}$ Guerra Mundial é um marco de grandes transformações, que colocam a pesquisa e o desenvolvimento científicotecnológico como elemento fundamental para o crescimento das economias nacionais, impulsionando novas descobertas e novas demandas. O processo de internacionalização acadêmica, surgiu como uma das respostas as demandas globais pressupondo que a cooperação e ações conjuntas são necessárias para lidar com um mundo cada vez mais complexo e competitivo (Van Der Wende, 2001; Souza \& Fleury, 2009; Antunes, 2005; Freitas, 2008, 2009), o que, sobremaneira, reflete similaridades com os processos de internacionalização de empresas (Mariotto, 2007). Mesmo assim, vale ressaltar que existe uma problemática em torno da definição do que é internacionalização e diversos autores, entre eles Warwick (2014) fala da pouca compreensão sobre o seu significado e do fato de que muitas universidades não detêm competências, conhecimentos e experiências gerenciais para lidar com os efeitos que o processo de internacionalização acarreta.

Knight (1994, 1997), declara que em boa medida o significado da internacionalização é derivado dos interesses que são buscados. Para ela, a definição mais comum é associada às atividades internacionais, como a educação multicultural, o treinamento intercultural, os estudos internacionais comparados ou a educação global. A autora propõe que a internacionalização seja considerada a partir da integração de quatro abordagens (Knight, 1994), a saber: a) A das atividades, como desenvolvimento curricular, intercâmbios, pesquisa e treinamentos conjuntos; b) A das competências ou o desenvolvimento de habilidades, conhecimentos, atitudes e valores nos membros das instituições (alunos, professores e staff) com foco mais internacional e intercultural; c) A do ethos ou a criação de uma cultura no campus que valoriza e estimula a educação internacional e os encontros interculturais, resultantes de consciência e comprometimento das várias instâncias da organização; e, d) A da perspectiva de que a internacionalização é um processo e que este deve ser incorporado na missão, nas políticas, no planejamento e no sistema de avaliação da qualidade 
nas instituições. Na literatura consultada, esta proposta se revela mais abrangente e objetiva para direcionar as análises sobre níveis ou graus de internacionalização, caso assumamos o pressuposto de que se trata de um processo que envolve variáveis quantitativas e qualitativas simultaneamente.

Jang (2009) traz um inventário de definições propostas por diversos autores, porém opta pela definição de Knight (1994), mencionada anteriormente. A autora investiga a relação entre internacionalização e qualidade no ensino superior, tema que tem despertado algumas dúvidas, como em Van Der Wende (1999), que diz não haver evidências de que esta relação seja positiva. Como este é o objetivo principal da investigação de Jang (2009), ela detecta em uma survey realizada com 750 faculdades e universidades norteamericanas pelo American Council on Education, em 2001, discrepâncias entre a retórica das instituições e suas práticas, especialmente em relação a programas, recrutamento de estrangeiros, ausência de menção de objetivos de internacionalização nos planejamentos estratégicos, pouca cobrança de requisitos de idiomas para entrada de alunos, bem como a exigência de trabalho ou experiência internacional para alunos de pós-graduação.

$\mathrm{Na}$ investigação conduzida pela própria Jang (2009) foram analisadas 77 instituições norteamericanas (dentre as quais aquelas que aparecem em primeiros lugares nos rankings mundiais mais importantes) tendo como variáveis a Internacionalização e a Qualidade da educação superior. A variável Internacionalização foi desmembrada em: a) estudantes internacionais no campus; b) alunos americanos no estrangeiro; c) professores e faculdades internacionalizadas; d) atividades de pesquisa internacional; e) curriculum internacional; e, f) suporte para a internacionalização. Do lado da Qualidade foram analisados os seguintes aspectos: i) competitividade da pesquisa; ii) competitividade da faculdade; iii) competitividade do curso de graduação; iv) competitividade do treinamento avançado; v) estabilidade financeira; vi) satisfação dos envolvidos; e, vii) reputação institucional. As conclusões apontam que em apenas duas dimensões não há evidências de impacto positivo entre internacionalização e qualidade do ensino: a relacionada com a estabilidade financeira e a relacionada com a internacionalização do curriculum.

Ainda em relação à qualidade, Reddy (2008) debate o papel das acreditações, cuja pertinência em um cenário que sofre modificações constantes é inquestionável, visto que elas podem proporcionar avaliações isentas, o estabelecimento de padrões de qualidade e fomentar o desenvolvimento interno das instituições através da busca de parâmetros que são aceitos mundialmente. Ainda que reconheça os méritos das acreditações, o estudo critica os aspectos normativos que não consideram os sistemas de governo locais, como se as definições de pares fossem autônomas e neutras. No entanto, essas definições representam sistemas de avaliação que variam, como o europeu, o asiático, o americano e o australiano. Cada um deles com a sua própria interpretação de mundo.

Assim como as definições variam, variam também as estratégias propostas por autores. No entanto, segundo Jang (2009), existe um consenso em relação aos seguintes aspectos: 1) inclusão do objetivo de internacionalização na missão da instituição; 2) encorajar a participação de estudos no exterior e prover financiamento para desenvolvimento de parcerias internacionais; 3) elevação do numero de alunos internacionais no campus; 4) promover e recompensar os resultados relacionados com atividades internacionais, inclusive programas e pesquisas com foco internacional; 5) obrigatoriedade da proficiência em idioma estrangeiro como requisito de entrada em cursos de pós-graduação.

No relatório da OCDE (2014) encontramos uma síntese de fatores que influenciam a decisão institucional para internacionalizar-se: i. Uma economia nacional mais interdependente e intercultural. ii. A elevação da demanda por educação superior e o valor percebido em se estudar em escolas de prestígio; iii. Minimizar o custo em sistemas de educação com poucos recursos; iv. Ter acesso a especializações e conhecimentos em áreas diferentes das providas pelo sistema local; v. Ampliação de receitas para as instituições que recebem alunos estrangeiros; e, vi. Ampliação estratégica do recrutamento de imigrantes altamente qualificados, subsidiando a política de imigração dos países receptores.

Existem no Brasil alguns estudos já consolidados, geralmente no formato estudo de caso (Stallivieri, 2004; Pimenta, 2006; Souza \& Fleury, 2009; Laus, 2012; entre outros), e que contribuem para uma compreensão sobre a internacionalização acadêmica. Dentre eles, um dos mais citados é o de Stallivieri (2004), que traça um breve histórico da cooperação universitária internacional, as modalidades que têm sido comumente usadas e analisa o caso da Universidade Federal de Caxias do Sul. Em suma, os estudos sobre a internacionalização acadêmica no Brasil, abrangem o desenvolvimento da internacionalização em um cronologia em quatro períodos: a) o dos professores visitantes nas jovens universidades brasileiras (décadas de 1930 a 1950); b) o da vinda de consultores norte-americanos e concessão de bolsas para mestrado e doutorado no exterior (décadas de 1960 a 1970); c) o da expansão e consolidação de programas de pós-graduação stricto sensu, com incremento da pesquisa e diferenciais competitivos (década e 1980 a 1990); e, o do amadurecimento da internacionalização gestada e financiada pelos governos e os primeiros investimentos da iniciativa privada, em virtude do crescimento da privatização da educação superior no Brasil, a partir de 2000 (Stallivieri, 2004; Pimenta, 2006; Souza \& Fleury, 2009; Laus, 2012). 
Conquanto os esforços sejam fragmentados tanto nas instituições de ensino quanto nas políticas de governo, temos exemplos da internacionalização como fundamento de algumas novas iniciativas, como universidades que foram criadas na última década sob o signo da cooperação internacional: UNILAB, UNILA e UFIA, além do programa Ciências Sem Fronteiras.

\section{MÉTODOS E PROCEDIMENTOS DE PESQUISA}

Este é um estudo de natureza qualitativa, baseado em duas pesquisas interligadas e complementares, com públicos diferentes, na mesma instituição, ou seja, EAESP/FGV. Para o tratamento dos dados foi utilizado o método do estudo de caso, fundado em história oral (VERGARA, 2008), bem como a técnica de análise de conteúdo (Bardin, 1977; Bauer \& Gaskell, 2000), a qual nos permitiu identificar aspectos de contexto, fases e etapas importantes do percurso de internacionalização da EAESP/FGV.

A aplicação da técnica de história oral, proposta por Vergara (2008), ocorreu acima de tudo na forma como conduzimos a elaboração do roteiro de entrevista e na maneira como estas foram conduzidas, junto ao corpus desta parte da pesquisa (Bauer \& Aarts, 2000; Tesch, 1990), o qual considerou três públicos-alvo diretamente envolvidos no processo de internacionalização da EAESP/FGV: a) sete exdiretores (entre os oito vivos; b) três ex-vices diretores; c) quatro coordenadores do International Office.

Optamos por realizar entrevistas semiestruturadas, as quais permitiam aliar temas prédefinidos - a partir dos temas abordados no referencial teórico deste trabalho sobre internacionalização acadêmica - e a liberdade e a espontaneidade necessárias para que os entrevistados relatassem fatos e momentos de suas experiências profissionais, em relação ao processo de internacionalização da EAESP/FGV, enriquecendo assim, a investigação. Nosso roteiro foi elaborado e segmentado em seis blocos, a partir do referencial teórico acerca da internacionalização acadêmica e conforme o objetivo proposto no trabalho. Isto é, abordamos nas pesquisas empíricas aspectos que consideramos essenciais para a análise da pergunta de pesquisa, os quais incluem: o capital intelectual disponível na instituição capaz de executar as decisões tomadas pelas diretorias; a qualificação internacional do corpo docente; elementos estratégicos fundadores do processo de internacionalização, seja a partir da perspectiva da construção de novos conhecimentos e especializações, seja a da abertura para interagir com diferentes culturas e sistemas educacionais; a compreensão do cenário acadêmico internacional, para o qual instituições de ensino superior devem dar respostas. Em suma, buscamos nos direcionar para a apreensão das decisões que envolveram aspectos da internacionalização da EAESP/FGV, decisões essas que só poderiam ser colocadas em prática por meio de competências reais e objetivas, os quais foram identificadas nos relatos coletados.

Com o auxílio do roteiro semiestruturado elaborado para a pesquisa, preocupamo-nos em oferecer aos entrevistados a maior liberdade possível para eles narrassem suas histórias e memórias sobre a internacionalização da EAESP/FGV, ao longo do tempo, da melhor maneiras que lhes conviesse. Com tal postura, a utilização as histórias orais coletadas mostraram-se pertinentes para a construção das narrativas e memórias acerca da história da EAESP/FGV, o que proporcionou uma compreensão mais detalhada acerca da rotas de internacionalização adotadas pela Escola.

O conjunto de dados empíricos foi interpretado com o auxílio da técnica de análise de conteúdo (Bardin, 1977; Bauer \& Gaskell, 2000), tendo os relatos e dados coletados nas entrevistas, sido organizados por meio de categorias temáticas selecionadas a partir do referencial teórico, bem como dos próprios dados recorrentes que emergiram das falas dos entrevistados. Isso requer entender que a análise dos dados foi procedida sobre as seguintes categorias: (i) percursos, decisões e caminhos da internacionalização; (ii) missão americana e corpo docente incial; (iii) PIM - Partinership in International Management; (iv) CRI - Coordenação de Relações Internacionais; (v) Acreditações e redes globais; (vi) programas internacionais e inseridos internacionalmente; (vii) EAESP/FGV e o lugar da estratégia; (viii) Inserção internacional do corpo docente; e (ix) envolvimento em atividades acadêmicas internacionais.

Foram convidados a participar da pesquisa todos os professores da EAESP, independente de seu tipo de contrato. Em face da acessibilidade a todo o quórum desejado de participante de pesquisa, recebemos 266 respostas para o questionário eletronicamente enviado, o que corresponde ao retorno de $100 \%$ ao questionário de pesquisa. Esse instrumento de pesquisa, que foi utilizado em complementação as entrevistas realizadas em campo, foi submetido a pré-teste junto a 20 professores da EAESP/FGV. Após alguns ajustes nas perguntas que compunha a ferramenta de coleta, consolidados um questionário de pesquisa abrangente e direcionado a revelar aspectos do processo de internacionalização do corpo docente atuante na EAESP/FGV.

\section{A instituição-objeto}

Em 1954 uma iniciativa do Ministério da Educação e Cultura e da Fundação Getúlio Vargas (FGV) culminou na celebração de um contrato entre a USAID - United States Agency for International Development $e$ a Michigan State University (MSU) para estabelecer em São Paulo a EAESP, com o objetivo de formar profissionais altamente qualificados para atender às necessidades do processo de 
industrialização e desenvolvimento do país. Em 1955 seguiram para os EUA oito candidatos aprovados em concurso para constituir o primeiro quadro docente brasileiro da escola. Desde a sua implantação, e durante os 12 anos seguintes, um grupo de 20 professores norte-americanos, conhecidos como Missão Americana, fizeram parte do corpo docente da escola (FGV/EAESP, 2007).

Tendo sido estruturada a partir do exemplo da MSU (Alcadipani \& Bertero, 2012), a EAESP desenvolveu currículos de cursos e programas de disciplinas, bem como definiu processos educacionais, usando bases metodológicas, técnicas de ensino e bibliografias norte-americanas, consideradas as modernas na área existentes na época. Professores brasileiros traduziram materiais didáticos, apostilas, casos e livros para uso dos alunos, que foram aos poucos se habituando à leitura dos originais; até hoje, a EAESP usa forte bibliografia norte-americana em muitas disciplinas e alguns cursos são ministrados totalmente em inglês em nível de graduação, mestrado e programas executivos.

Uma visão numérica da EAESP em 2015 nos indica que são aproximadamente 2.200 alunos nos cursos diurnos de graduação (Administração de Empresas e Administração Pública), 550 alunos de cursos de especialização, 85 alunos no nível de mestrado acadêmico, 170 alunos em curso de doutorado e uma movimentação internacional anual próxima de 1000 estudantes que vão para o exterior e que vêm do exterior em programas de intercâmbios, que participam de titulação de double degree, de cursos de curtas duração destinados a executivos e de mestrados profissionais.

Podemos dizer que se é um fato que a EAESP nasceu norte-americana, ela também se assemelha ao modelo das "grandes écoles" francesas, caracterizadas pelo seu tamanho menor que os sistemas universitários, maior grau de autonomia acadêmica, forte seleção para entrantes, equipe de professores composta por acadêmicos e profissionais experientes do mercado, pedagogia que enfatiza integração teoria e prática, cooperação com o meio empresarial e setor público bem como abertura á internacionalização. Em cursos de graduação e pós-graduação estrito senso, o processo seletivo de alunos inclui como eliminatória a prova de inglês.

A EAESP é uma das unidades da FGV, cujo papel como mantenedora é o de estabelecer definições estratégicas, prioridades e coordenar os recursos e as ações desenvolvidas pelas suas partes, que têm considerável grau de autonomia acadêmica. A missão da FGV é a de "Avançar nas fronteiras do conhecimento na área das Ciências Sociais e afins, produzindo e transmitindo ideias, dados e informações, além de conservá-los e sistematizá-los, de modo a contribuir para o desenvolvimento socioeconômico do país, para a melhoria dos padrões éticos nacionais, para uma governança responsável e compartilhada, e para a inserção do país no cenário internacional" (FGV, 2015).

A Revista de Administração de Empresas (RAE), que é um importante ativo acadêmico da EAESP, foi lançada em 1961 e jamais foi interrompida, situação inédita em um cenário que atravessou 20 anos de ditadura militar. Ela teve um papel fundamental na profissionalização de executivos e foi responsável pela disseminação de técnicas e práticas de gestão, especialmente dirigidas ao mundo empresarial, porém aos poucos foi assumindo uma face mais acadêmica e teve a sua versão eletrônica iniciada em 2002. Tem se mantido como umas das principais mídias de negócios no país.

As iniciativas internacionais, excetuando as relações com a MSU, se iniciaram em 1975 quando a EAESP se integrou á rede PIM (Partnership in International Management), para desenvolver intercâmbio de estudantes de cursos de pós-graduação stricto sensu em conjunto com as melhores escolas internacionais de negócios da época. Em 1991 foi criada a área administrativa dedicada à gestão das relações internacionais na EAESP e 1996 ela se consolidou como a Coordenação de Relações Internacionais (CRI). Aos poucos a EAESP ampliou sua o escopo de sua atuação e diversificou suas parcerias.

\section{RESULTADOS}

Como dissemos antes, apresentaremos aqui os resultados das duas pesquisas empíricas. A primeira teve seu foco nos percursos, decisões e ações efetivados pelos gestores da EAESP/FGV ao longo dos anos. Este material foi consolidado e submetido á análise de conteúdo, gerando seis categorias que determinam o processo de internacionalização da EAESP. O critério básico para a definição destas categorias é o de maior frequência nas falas dos pesquisados. A segunda, realizada com o corpo docente, enfatizou a formação acadêmica e envolvimentos internacionais dos pesquisados.

\section{I) Percursos, decisões e caminhos da internacionalização}

As categorias de análise serão apresentadas em uma ordem mais ou menos cronológica, sem ser linear, uma vez que elas se influenciam mutuamente. As categorias que surgiram dos dados foram: a) Missão americana e corpo docente inicial; b) PIM; c) CRI; d) Acreditações e redes globais; e) Programas internacionais e com inserção internacional; g) EAESP - FGV: o lugar do planejamento estratégico.

\section{a) Missão americana e corpo docente inicial}

A EAESP foi instituída pela Fundação Getúlio Vargas em 1954, resultante de um acordo entre os 
governos americano e brasileiro, que recebeu ajuda técnica de um grupo de professores da Michigan State University (MSU), denominado "Missão Americana". $\mathrm{O}$ acordo previa ainda o recrutamento e a formação de jovens professores para substituírem a Missão, em época oportuna.

O grau de internacionalização da EAESP no momento de sua criação foi muito elevado em vários aspectos: a escola nascente contava com professores americanos provenientes de uma universidade americana de prestígio, dando aulas em inglês, usando notas de aula, estudos de caso e livros americanos em inglês, usando sistemas de avaliação e educando jovens em conceitos modernos de administração de empresas. Mais do que isso, a Missão Americana trazia uma concepção inédita no Brasil de como uma escola de negócios poderia ser organizada e operada.

Embora a EAESP tenha nascido de um relacionamento internacional, o seu processo de internacionalização desenvolveu-se apenas mais tarde, em virtude de sua criação ter coincidido com um momento da história nacional em que o país foi profundamente moldado pela ação do governo, que instituiu políticas de estímulo à produção local, ressaltando-se a política de substituição de importações e o Plano de Metas (1956) do presidente Kubitschek. O Brasil voltou-se para dentro, inclusive nas atividades acadêmicas.

As circunstâncias de sua formação conferiram à Escola uma marca genética, um dote inestimável. O seu sucesso subsequente foi em parte devido ao esforço dos que aderiram ao seu projeto e em parte devido a essa gênese ou a este DNA internacional. Depois da experiência da própria criação da EAESP, houve mais um passo importante na sua internacionalização inicial: cerca de uma dúzia de Professores Assistentes, recémcontratados pela escola, foram enviados à MSU para fazer o MBA. Professores admitidos posteriormente foram enviados a outros países e outras escolas no exterior, alguns para uma permanência curta, outros para uma mais longa, como no caso dos programas de doutorado.

\section{b) PIM - Partnership in International Management}

O PIM é um consórcio internacional de escolas de administração de renome e teve seu inicio em 1973. A EAESP foi convidada a se juntar á HEC/França, NYU/EUA e London Business School/Inglaterra e é membro da rede desde 1975. Atualmente são 62 escolas de prestígio, representando 35 nações, que proporcionam cooperação internacional prioritariamente para cursos de graduação. Trata-se de uma rede reconhecida regional e globalmente devido ao nível de excelência das instituições participantes. A EAESP tem participado dos cargos que definem políticas e estratégias globais, sendo membro permanente dos comitês e boards internacionais.

A participação da EAESP no PIM tem sido considerada como um fator fundamental de visibilidade da escola no mundo, em virtude do reconhecimento, por parte das instituições-pares, de sua qualidade acadêmica e de seu potencial como importante player no mundo educacional internacional. $\mathrm{O}$ aval de tantas instituições de prestígio foi decisivo para a consolidação de outras parcerias mundiais, portanto a entrada no PIM pode ser considerada o momento em que de fato a EAESP começou a se internacionalizar. Sendo a única instituição na América Latina participante da rede, ela passou a fazer intercâmbio de alunos de pós-graduação e posteriormente de graduação, a participar de reuniões internacionais para discussão de políticas e programas, decidir sobre parcerias preferenciais e ajustamento de programas conjuntos. Novos membros latino-americanos foram aceitos somente a partir de 1998 .

O PIM foi o momento em que a escola passou a vivenciar o mundo e não apenas os Estados Unidos. Foi o momento em que percebeu que a cooperação poderia ser expandida para outras instituições e que o volume de intercâmbio demandava uma estruturação organizacional para gerir mais eficientemente esta atividade.

\section{c) CRI - Coordenação de Relações Internacionais}

Os intercâmbios da rede PIM eram inicialmente destinados aos alunos de pós-graduação stricto sensu, notadamente os do curso de mestrado. A sua gestão era responsabilidade da coordenação de pós-graduação (CPG), que se limitava á realização da seleção de alunos que iriam viajar e a recepção e matrícula dos alunos que chegavam.

A década de 1980 foi difícil para o Brasil, porém a escola conseguiu manter um fluxo razoável de intercambistas. Em um dos melhores anos da "década perdida", para o $1^{\circ}$ semestre de 1987 foram selecionados 11 alunos do mestrado para estudar na NYU/EUA, ESADE/Espanha, HEC/França, ESSEC/França, Bocconi/Italia, Universidade de Colônia/Alemanha e Universidade de Viena/Áustria. Sabe-se que praticamente todos estes alunos continuaram seus estudos de doutorado e ingressaram posteriormente na vida acadêmica.

Em 1991 as atividades relacionadas á gestão internacional foram concentradas em um setor específico, sob a responsabilidade de uma professora com experiência internacional. A elevação rápida do número de parcerias, o aumento de volume das atividades internacionais, a mudança de público da pós-graduação para a graduação e a necessidade de maior autonomia do setor para representar a escola perante suas parceiras existentes e potenciais, foram fatores que influenciaram a formalização e estruturação da CRI em bases mais profissionais nos anos seguintes.

À medida que a CRI foi ganhando maior importância, o seu foco foi se ampliando. Antes concentrada nas atividades burocráticas demandadas pela relação de intercâmbio, a coordenação passou a se envolver progressivamente em atividades mais 
relacionadas com novas parcerias e programas internacionais, subsidiar a diretoria em suas decisões sobre o assunto e prospectar novas possibilidades.

\section{d) Acreditações e redes globais}

Desde meados dos anos 1970, a EAESP tem buscado se inserir em parcerias internacionais, como o PIM, destacando o seu pioneirismo em oferecer aos seus alunos opções para realizar parte de seus estudos no exterior, como um diferencial e resposta à nova configuração do mercado educacional nacional e internacional. As ações da EAESP tem assumido a forma de acordos de double degree com escolas de grande expressão internacional, como a iniciada em 2000 com a HEC/França para programas de MBA. Este novo tipo de parceria também tem sido realizada com diversas instituições, como: Universidade Torcuato de Tella (Argentina), IE/Espanha, Universidade Nova de Lisboa/Portugal, Universidade Texas em Austin/EUA, SciencePo/França, Universidade Luigi Bocconi/Itália, Columbia University/EUA, Northeastern University/EUA, St. Gallen/Suiça e Tsinghua University/China.

Destaca-se também que os anos 2000 foram marcados pelas acreditações internacionais da EAESP, como a da AACSB - The International Association for Management Education (2000), a do EFMD/EQUIS European Foundation for Management Development (2001) e a da AMBA - Association for MBAs (2004), tornando a EAESP a primeira escola da América Latina a obter a "triple crown". Um de nossos entrevistados afirma que são aproximadamente 22 mil escolas de negócios no mundo, 600 delas são acreditadas pela AACSB e somente 57 têm as três validações acima. Certamente este status exige uma estrutura de registros, a definição de metodologias específicas e a determinação padrões acadêmicos mais rigorosos, que permitem a estas instituições fazer as suas avaliações periódicas para recredenciamento. A EAESP vem colhendo os frutos que os esforços de fazer parte de um clube dos raros geram, seja em visibilidade e reconhecimentos que estes avais proporcionam, sejam para novas parcerias, seja para fortalecimento e ampliação dos vínculos mais antigos.

Além destes credenciamentos, a EAESP tem participação em boards, redes e associações educacionais internacionais como a CEMS Community of European Management Schools, o CBS - Council on Business Society, a GNAM - Global Network for Advanced Management, a GNPP - Global Public Policy Network e o SUMAQ, congrega instituições líderes na América Latina. Em 2012, a EAESP instituiu seu próprio International Advisory Board, tendo como membros a PUC/Chile, Columbia University, Cambrige University, HEC/Paris, Instituto de Empresa/Espanha e ESAN/Peru.

\section{e) Programas internacionais e inseridos internacionalmente}

Em 2001 a EAESP lançou o programa Doing Business in Brazil (DBB), destinado a executivos, profissionais internacionais e acadêmicos de escolas reputadas, com interesse em compreender o ambiente de negócios do Brasil. Trata-se de um programa feito de acordo com a necessidade do público interessado, realizado através de palestras com especialistas e visitas institucionais, durante uma ou duas semanas, que geralmente inclui o debate de aspectos econômicos, institucionais, jurídicos, sociais e culturais do Brasil e da América Latina. O programa completou em 2015 a sua $14^{\mathrm{a}}$ edição.

O primeiro programa acadêmico internacional da EAESP, chamado OneMBA, nasceu em 2002 da parceria de cinco instituições de renome, sediadas em quatro continentes. É um programa mundialmente reconhecido, que dá dois diplomas de MBA: um assinado pela instituição local e outro assinado pelas cinco instituições parceiras. Os parceiros atuais são: School do Management Xiamen University (China), Erasmus University (Holanda), University of North Carolina at Chapel Hill (USA), EGADE (México) e EAESP/FGV (Brasil)

Em 2004 a EAESP tornou-se membro associado da CEMS Alliance (Community of European Management Schools), que ampliou seu escopo de internacionalização convidando algumas instituições não européias, reunindo 27 escolas em 4 continentes. Em 2008 a EAESP foi admitida como membro pleno, passou a integrar o Strategic Board Members e em 2011 foi anfitriã do CEMS Executive Board Meeting, o primeiro encontro desta natureza realizado nas Américas.

A entrada na escola na aliança CEMS impulsionou a criação, ainda em 2004, do Internacional Program in Management (IPM) na pósgraduação, inteiramente ministrado em inglês. Este IPM é o precursor do MPGI - Mestrado Profissional em Gestão Internacional, com a participação de alunos da rede CEMS e com vários acordos de dupla titulação com várias instituições.

Os programas de pós-graduação em níveis de mestrado e doutorado em Administração de Empresas e Administração Pública também têm participado dos esforços de internacionalização da EAESP, através da contratação de professores estrangeiros no sistema "joint appointment", que permite a dupla vinculação institucional. Considerando que é exigido dos alunos um estágio doutoral no exterior de pelo menos seis meses, alguns destes professores tornam-se seus supervisores de teses quando em suas universidades de origem. Esses programas são avaliados pela Capes atualmente com notas 7 e 5 respectivamente.

Também professores da EAESP, de diferentes linhas de pesquisas, têm sido convidados para ministrar cursos periódicos em instituições estrangeiras, como professores visitantes, abrindo a possibilidade de estabelecer parceiras interinstitucionais e de interação entre colegas de diferentes países. 


\section{II) EAESP/FGV: o lugar da Estratégia}

A grande maioria de nossos entrevistados foi hesitante ao falar do processo de internacionalização da EAESP como resultante de uma estratégia formal, definida, explícita e direcionadora da instituição. Em boa medida ficou subentendido que a internacionalização da escola tem sido produzida por várias oportunidades que foram bem aproveitadas, como os convites para participar no PIM, AACSB e CEMS. Uma vez aceitos estes convites, a escola tem se desdobrado para atender ao que lhe é esperado e tem apresentado os requisitos para continuar a fazer parte destas alianças. A sua boa imagem internacional é fruto mais destas respostas apropriadas que de iniciativas mais agressivas em um cenário cada vez mais competitivo mundialmente. Merece destaque o compromisso das diretorias assumidas após 2007 com ênfase em uma política de internacionalização, ainda assim os pesquisados não classificaram esta posição como sendo uma estratégia formal da EAESP, que exige além de determinação, aporte de recursos para ser operada sem solução de continuidade.

Os entrevistados parecem considerar que o aspecto internacional na EAESP não é assumido com a força necessária em um mercado mundial competitivo, através de iniciativas mais explícitas e investimento nas condições que poderiam gerar resultados mais consistentes e contínuos. Por outro lado, eles parecem também entender que as culturas da EAESP e da FGV denotam um grande orgulho de seu papel nacional e de sua reputação, sendo a internacionalização um fator desejável, mas não primordial.

Mais que uma eventual miopia, a compreensão interna, o ritmo e a profundidade do processo de internacionalização da EAESP parecem ser consequência também da ausência de uma política internacional integrada da própria FGV. O consenso que une os nossos entrevistados é o de que EAESP é o nome conhecido nas escolas de negócios no mundo e que a FGV, nos últimos anos, tem sido identificada como um importante Think Tank, porém sem o reconhecimento nos mercados educacionais acadêmicos e executivos mundiais.

Uma vez que a EAESP é uma unidade da FGV, com autonomia apenas acadêmica, em algum momento ela encontrará os limites estruturais e organizacionais que a implantação de uma estratégia internacional mais proativa impõe.

\section{a) Inserção internacional do corpo docente}

A segunda pesquisa empírica foi realizada com o corpo docente da EAESP entre abril e junho/2015 envolvendo 266 professores, de diferentes tipos de contratos de trabalho (tempo integral, NDP e parcial). Este grupo revela 16,4 anos de tempo médio de trabalho. A tomada de decisões ou a definição de políticas internacionais por instituições de ensino superior e agências avaliadoras levam em consideração a preparação, envolvimento e qualidade dos profissionais que irão executá-las. Ou seja, neste caso, pelo menos em um primeiro momento, a estratégia segue a estrutura, ainda que a modifique depois.

É consenso na literatura que a formação ou a complementação de formação acadêmica no exterior, especialmente em instituições de renome, proporciona a aquisição de novos conhecimentos (conteúdos temáticos, novas áreas e especializações, métodos), desenvolve e amplia as competências interculturais (convívio e adaptação social e cultural a novos códigos linguísticos, institucionais e profissionais) e compreensão mais aprofundada do cenário global da educação superior, com uma maior interação dos setores econômicos e governamentais locais ou regionais. Com base nestes fundamentos, obtivemos dos pesquisados os seguintes dados:

\section{b) Curso de doutorado}

Em relação á titulação de Doutor, $84 \%$ do corpo docente da EAESP é portador deste título, cujas áreas predominantes são Administração de Empresas, Economia e Ciências Sociais. A grande maioria dos cursos foi realizada no Brasil, que há muito dispõe de programas nestas áreas, estando consolidados e sendo bem avaliados pelas agências responsáveis pelo ensino superior. Muitos destes acadêmicos realizaram parte de seus programas no exterior, com permanência que varia de 6 meses a 18 meses, em uma modalidade conhecida como programa bolsa sanduiche.

\section{c) Estágio pós-doutoral}

Foram realizados 50 programas de estágios doutorais ou pós-doutorado pelo corpo docente, dos quais $77 \%$ foram feitos no exterior durante os últimos 10 anos. O Gráfico 01 indica os países escolhidos pelos professores para a realização de seus pós-doutorados. 


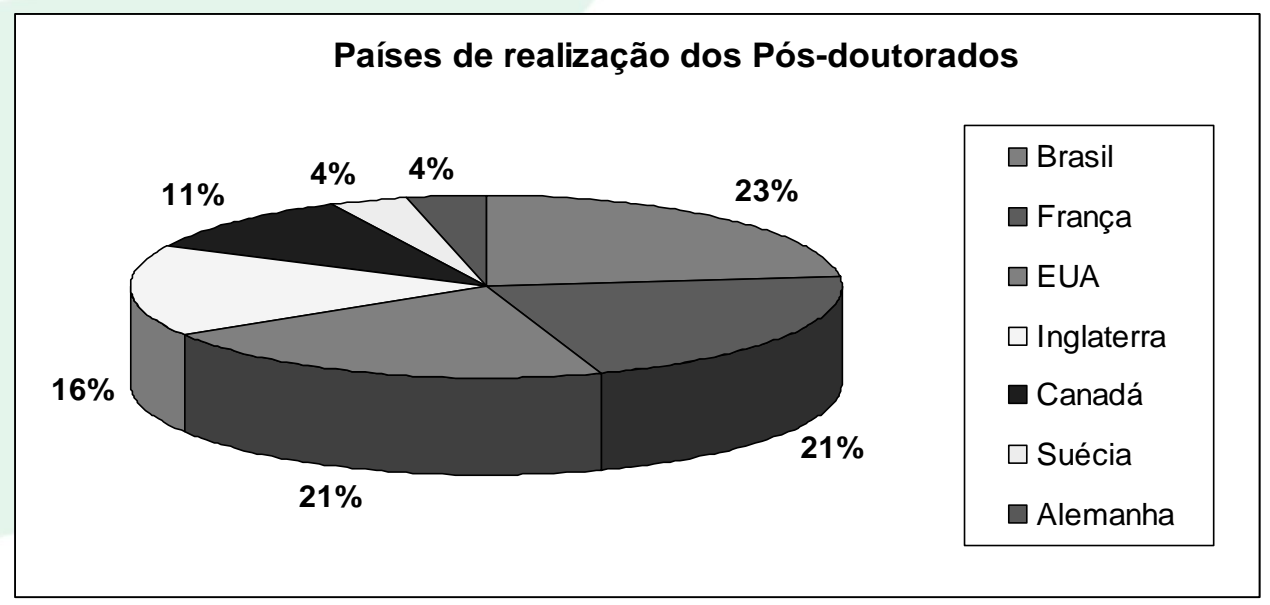

Gráfico 1 - Países de realização dos programas de pós-doutorado

Fonte: dados da pesquisa

Como podemos notar, a destinação internacional de $21 \%$ dos programas de pós-doutorado se deu na França, $21 \%$ os Estados Unidos, $16 \%$ a Inglaterra, $11 \%$ o Canadá, $4 \%$ a Suécia e $4 \%$ a Alemanha. Em relação á competência linguística percebe-se há uma concentração de $37 \%$ dos professores em países de língua inglesa e $32 \%$ em países francofones, o que demonstra que o corpo docente, dependendo de seus interesses de pesquisa, não se limita ao domínio de um único idioma.

Sobre as instituições internacionais escolhidas pelos professores para realização de seus programas de pós-doutorado, o Gráfico 02 apresenta as seis universidades mais escolhidas pelo corpo docente da Escola.

\section{Instituições internacionais mais escolhidas para pós-doutorado}

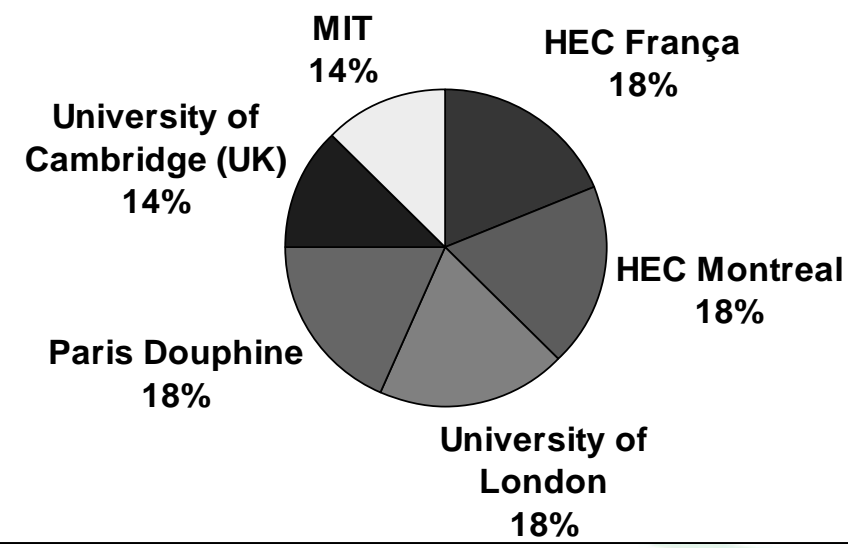

Gráfico 2 - Seis instituições internacionais mais escolhidas para pós-doutorado

Fonte: dados da pesquisa

As instituições francofones (Universidade Paris Dauphine, HEC França e Canadá) correspondem a $54 \%$ das universidades internacionais nas quais o corpo docente da EAESP/FGV realizou seus programas de pós-doutorado. Em seguida, instituições de língua inglesa aparecem com $46 \%$, sendo as britânicas com $32 \%$ e a norte-americana MIT com $14 \%$ da preferência dos professores. Estes dados revelam uma diversidade não apenas de filiações teóricas e abordagens, como competências linguísticas nos dois idiomas mais utilizados nos encontros acadêmicos ocidentais mais reputados.

d) Envolvimento em atividades acadêmicas internacionais

Foram analisados os fatores que consideramos como os mais significativos quando da avaliação de 
inserção internacional de professores e instituições pelas agências de fomento e desenvolvimento do ensino superior no Brasil, bem como nos processos de recredenciamento das agências internacionais acreditadoras. Os detalhes sobre os dados da EAESP estão dispostos no Gráfico 03, que apresenta as atividades internacionalização realizadas pelo corpo docente da Escola, considerando os últimos dez anos de suas atividades profissionais. Este período foi escolhido em virtude do tempo necessário para desenvolvimento, escolha e amadurecimento de parcerias entre colegas e instituições.

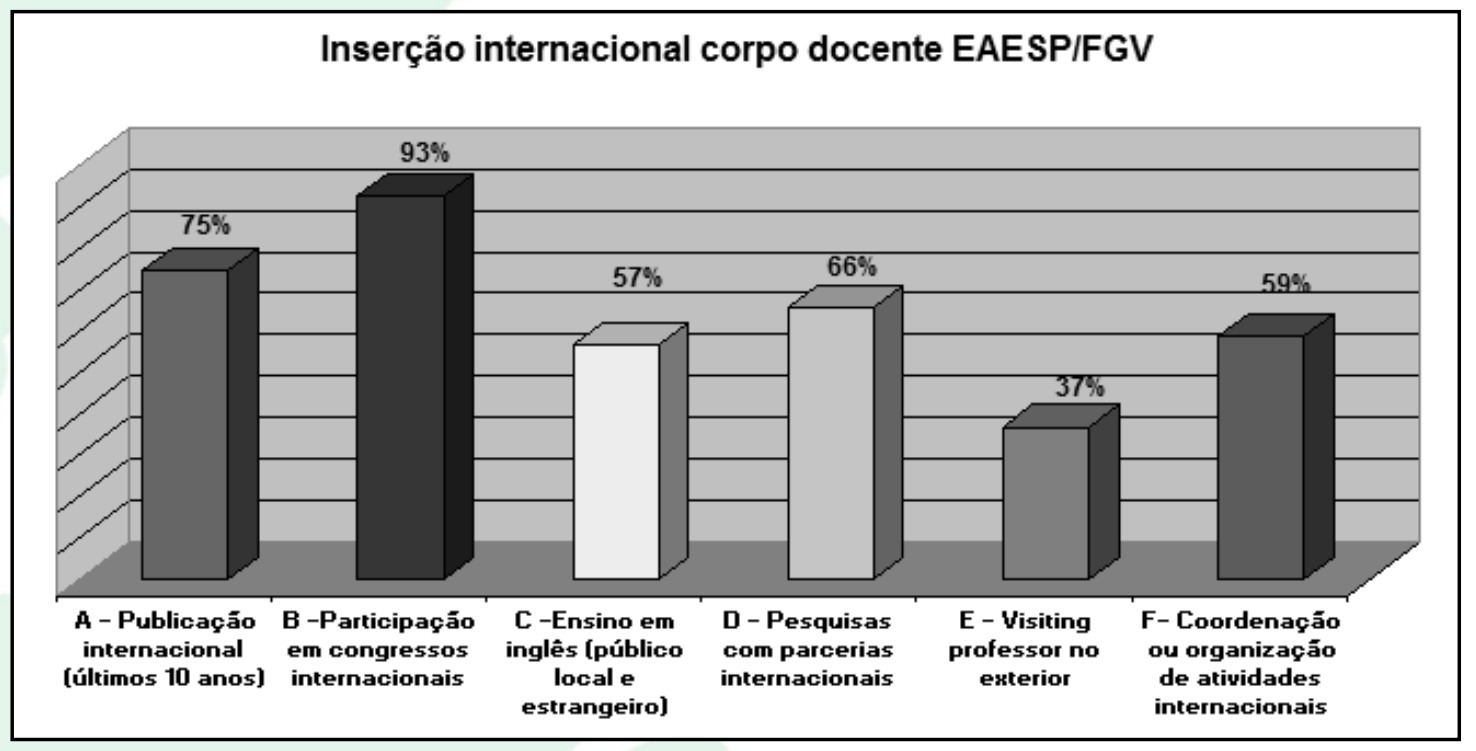

Gráfico 3 - Atividades de inserção internacional do corpo docente EAESP/FGV

Fonte: dados da pesquisa

Como podemos observar, os dados levantados na pesquisa interna na EAESP/FGV revelam que: a) $75 \%$ do seu corpo docente publicaram internacionalmente nos últimos 10 anos; b) $93 \%$ dos professores participaram de congressos internacionais nos últimos 10 anos; c) $57 \%$ dos professores ensinam ou ensinou em inglês em cursos da EAESP direcionados para alunos estrangeiros; d) $66 \%$ estão envolvidos em parcerias de pesquisa, publicações e cursos com colegas estrangeiros; e) $37 \%$ dos professores têm desenvolvido atividades de ensino regularmente em outros países; f) 59\% coordenaram ou organizou atividades acadêmicas internacionais.

Infelizmente não dispomos de dados internacionais para comparar estes desempenhos com os de outras instituições, em virtude dos estudos disponíveis serem basicamente os produzidos em países de língua inglesa, portanto competências linguísticas dos docentes não são consideradas (Jang, 2009; Warwick, 2014) ou estudos europeus, cujas fronteiras são fáceis de serem cruzadas e ser europeu é sinônimo de ser internacional.

Dentre os critérios de avaliação da AACSB sobre o grau de internacionalização das instituições postulantes a credenciamento ou recredenciamento são analisados aspectos como mix de nacionalidades de professores, percentual de professores visitantes, percentual de professores da instituição com experiência internacional, competências linguísticas, envolvimento em pesquisa conjunta internacional e publicações internacionais. Uma vez que mais instituições busquem serem acreditadas por esta e/ou outras agências, a tendência é que estudos sobre estes aspectos gerem uma massa crítica que permita maior aprofundamento de análises sobre o tema, inclusive a construção de alguns indicadores passíveis de serem comparados, ainda que pesem as realidades locais distintas.

\section{DISCUSSÕES E NOTAS FINAIS}

Ao investigarmos as rotas da internacionalização da EAESP/FGV notamos uma ambiguidade à medida que existem discursos, práticas e resultados que testemunham uma trajetória bem sucedida, mas, ao mesmo tempo, a existência de uma comunidade que parece não compreender ainda a essência do processo 
ou este como uma condição indispensável para se existir ou se manter no futuro, como nos advertiu Warwick (2014). Quer dizer, a partir da história da EAESP/FGV, podemos considerar que a internacionalização ainda não é vista como condição sine qua non para continuar existindo no mercado educacional no longo prazo, cuja concorrência é local e global e a velocidade de atuação é cada vez mais acelerada.

No entanto, os resultados da pesquisa sobre formação ou capacitação internacional do corpo docente da EAESP/FGV - vide (gráfico 03) evidenciam realizações concretas, como participação em congressos (93\%), publicação internacional (75\%) e desenvolvimento de pesquisas com parcerias internacionais $(66 \%)$, que apresentam desempenhos que podemos considerar como bons. $\mathrm{O}$ ensino de disciplinas em inglês (57\%) em si não é conclusivo, pois depende das ofertas de disciplinas e cursos que demandam esta competência; torna-se necessário investigar se a escola teve demanda reprimida nestes cursos em virtude desta variável. $\mathrm{O}$ índice mais baixo apresenta $37 \%$ de atividades como visinting professor no exterior, seguido de $59 \%$ em atividades de coordenação ou organização de eventos internacionais. Ser professor visitante em outra instituição é em boa medida resultado de um convite feito por quem conhece o trabalho do convidado e sua reputação ou uma instituição é motivada por determinado tema e crê que seus alunos poderão ser beneficiados com a visita de alguém que pesquise o assunto. Por outro lado, a organização de eventos internacionais depende de fontes de financiamentos; a crise de 2008 atingiu muitos países, reduzindo orçamentos públicos e privados para viagens e participações em eventos internacionais, especialmente aqueles em lugares mais distantes. Ademais, também contam o prestígio do evento e da instituição-anfitriã, o esforço pessoal dos organizadores, tamanho de sua network, valorização da atividade no sistema de avaliação institucional e entre pares.

Estas atividades já desenvolvidas podem ser vistas como demonstrações reais de interesses dos docentes e da disposição da instituição em investir nelas, ainda que esta disposição possa ser bastante melhorada; como por exemplo, o caso de pósdoutorados, cuja média é menor que $2 \%$ do corpo docente por ano, desempenho insignificante em um mercado que tem na qualidade e atualização o seu grande diferencial. Capital intelectual desatualizado é desvalorizado!

Custos ou Investimentos de internacionalização? Em virtude do caráter continuado do uso de recursos financeiros para atividades de internacionalização, consideramos investimentos feitos pela EAESP nas seguintes rubricas: a) em mobilidade, intercâmbios e representações institucionais (acordos sobre taxas com parceiros, viagens, diárias, ajudas e taxas diversas); b) em construção de conhecimento e divulgação (custos de pesquisa, participações em congressos, abatimentos de créditos, professores visitantes e contratos de joint appointement, bolsas para assistentes, prêmios de incentivos); c) formação e capacitação (licenças sabáticas, pós-doutorados, treinamentos tecnológicos, metodológicos e linguísticos para corpo docente e funcionários de apoio); d) em sistemas de informações (estruturas organizacionais, administrativas e gerenciais para prospecção, manutenção e expansão de atividades internacionais); e) em comunicação e imagem institucional (mídias, traduções, instalações físicas, webpages). Oferecemos uma visão de modalidades de investimentos que conseguimos captar no levantamento empírico, porém não estamos assumindo que o seu volume seja suficiente. Temos claro que investimento é o resultado de uma política ou diretriz organizacional.

Considerando os dados sobre a qualidade dos investimentos da EAESP, os depoimentos nas entrevistas e a natureza das atividades desenvolvidas pelos professores, retomamos as abordagens propostas por Knight (1994, 1997) para verificarmos em que medida este processo de internacionalização responde a elas: a) Em relação às atividades de internacionalização (intercâmbios, programas e pesquisas conjunta, congressos, acreditações), os dados suportam a conclusão de que a EAESP apresenta alto desempenho; b) Em relação às competências ou habilidades de alunos, professores e staff para desenvolvimento de atividades internacionais, consideramos que a EAESP apresenta desempenhos medianos e limitados principalmente pela fluência do idioma inglês, não apenas por parte do corpo docente, mas pelos membros das áreas administrativas, inclusive os que lidam diretamente com alunos estrangeiros; c) Em relação á existência de um ethos ou cultura organizacional que valoriza e estimula a educação internacional e intercultural, os dados sugerem que os membros da instituição não valorizam este item como fundamental, nem a incorporação da internacionalização como um valor organizacional e consequente comprometimento para com ele; d) Em relação á perspectiva de internacionalização como processo e que deve ser incorporado á missão, políticas e sistemas de avaliação, a EAESP evidencia a internacionalização como um objetivo explícito a ser continuamente buscado e o considera nos seus diversos sistemas de avaliação como variável importante, porém este processo não é parte da missão da organização, possivelmente pelo fato de ser ela uma unidade que segue a missão e estratégias definidas pela FGV.

Apesar de a EAESP não ter uma missão própria, ela tem uma cultura organizacional, fruto de sua história, opções, subjetividades e processos de aprendizagem de seus grupos ao longo do tempo. Esta cultura, que começa com os valores da missão americana e neles constrói seus alicerces, se complementam com valores da sociedade paulista, com forte ênfase na ética do trabalho, pluralidade e meritocracia. Uma vez que internacionalização passou a ser um objetivo explicito, com intencionalidade 
claramente definida, apenas a partir de 2007 e a cultura organizacional é um processo de construção lenta, parece razoável supor que à medida que as práticas ligadas á atividades internacionais se consolidem de forma consistente com o discurso organizacional, a internacionalização pode deixar de ser apenas uma variável a ser gerida e passe a ser algo incorporado pelos membros da instituição como um valor no cotidiano.

Considerada inicialmente na instituição como intrusão, hoje assumidas de forma natural como um marco importante na história da EAESP, as acreditações (AACSB, EFMD, AMBA) tem sido vistas como um fator crucial para novas parcerias e projetos já estabelecidos, em particular junto às instituições mais renomadas mundialmente, além de gerar parâmetros de equivalência internacional de qualidade. Ainda, a inserção recente em redes, com objetivos mais ambiciosos que a mobilidade estudantil, como a produção conjunta de conhecimento, desenvolvimento de programas e currículos, revela um novo status assumido pela instituição frente a seus pares e concorrentes (REDDY, 2008).

Em relação a fatores que limitam uma ação mais ousada e proativa da EAESP podemos citar: a) a inabilidade em transformar o aprendizado intercultural de seus membros em aprendizado intercultural organizacional, construindo uma mentalidade que valoriza a diversidade cultural e acolha com naturalidade as diferenças do mundo (Bueno \& Freitas, 2015; Davel, Dupuis \& Chanlat, 2008; Freitas, 2008); b) pouca cooperação com países vizinhos ou em estágio de desenvolvimento igual ou inferior ao do Brasil; c) pouca cooperação entre agentes nacionais e órgãos internacionais multilaterais ligados á educação superior; d) o Brasil é um país emergente, com história isolacionista, idioma pouco falado internacionalmente, elevado custo Brasil e suas conjunturas oscilantes; e, e) mercado internacional dominado por universidades do primeiro mundo, com fortes tradição e reputação.

Entendemos, ainda, como imperativo para um processo mais aprofundado de internacionalização que EAESP e FGV desenhem juntas estratégias explícitas e constituam os meios necessários para efetivamente serem concretizadas em colaboração, visto que a grandeza de uma é a grandeza da outra. Aqui talvez Weick (1976) e Jang (2009) possam ser bastante úteis.

Por fim, considerando toda a abordagem teórico-empírica sobre as rotas da internacionalização acadêmica da EAESP/FGV, entendemos que a maior contribuição deste trabalho é termos olhado para a realidade brasileira, por meio de uma das principais escolas de negócios do país e, assim, atribuir a importância devida ao debate sobre internacionalização das instituições de ensino superior, uma vez que elas são uma das mais significativas fontes de formação e aperfeiçoamento do capital intelectual, responsáveis pela qualificação de profissionais que atuarão na busca de respostas que contemplem o desenvolvimento interno de seus países e a sua maior participação na economia mundial.

Em face de seu recorte teórico-metodológico deste trabalho, sabe-se que esta pesquisa possui limitações. Mas espera-se que as suas eventuais limitações sejam supridas ao ser reforçado, por meio das contribuições geradas neste trabalho, o interesse de pesquisa sobre os processos de internacionalização acadêmica em contexto brasileiro. Assim, espera-se que estudos futuros possam igualmente avançar no conhecimento, tanto teórico quanto prático, sobre essa temática e contexto sócio-político-cultural, o qual constitui um dos arranjos capazes de influenciar os processos de mudanças locais e globais, ao ser a nação que ocupa a $7^{\mathrm{a}}$ posição econômica mundial (Global, 2015), por exemplo.

Como agenda para futuras pesquisa, lançamos algumas proposições para o avança do conhecimento sobre as práticas de internacionalização acadêmica, a saber: i) estudos que enfoque o debate sobre a importância da internacionalização, enquanto ação estratégica, para a legitimação organização no contexto local-global; ii) pesquisas que enfoque na discussão sobre a questão da expansão de estratégias internacionais associadas (ou não) as experiências acadêmicas e de inserção internacional dos gerentes acadêmicos que deliberam tais estratégias em instituições de ensino no Brasil; e, iii) investigações que debatam a legitimidade das estratégias de internacionalização acadêmica, enquanto mecanismos que estimulam processos de construção de sentido, em relação ao modo com as pessoas e organizações significam uma da instituição de ensino em seu contexto local e global.

\section{REFERÊNCIAS}

Adler, N. J. (2000). International dimensions of Organizational Behavior. Canadá: South Western/Thomson.

Alcadipani, R., \& Bertero, C. O. (2012). Guerra fria e ensino do Management no Brasil; o caso da FGVEAESP. Revista de Administração de Empresas, 52(3): 284-299.

Allemand, S. (2004). La mobilité comme capital. Sciences Humaines, 145: 20-22.

Antunes, F. (2005). Globalização e europeização das políticas educativas: percursos, processos e metamorfoses. Sociologia, Problemas e Práticas, 47: $125-143$.

Bennel, P., \& Pearce, T. (2003). The internalization of higher education: exporting education to developing and transitional economies. International Journal of Educational Development, 23: 215-232. 
Bueno, J., \& Freitas, M. E. (2015). Representações sociais e ambiente intercultural nas organizações. In: Moura, C. P., \& Ferrari, M. A. (Orgs). Comunicação, Interculturalidade e Organizações: faces e dimensões da contemporaneidade. Porto Alegre, EdiPUCRS, pp. 193-210.

Burns, T., \& Stalker, G. M. (1961). The Management of Innovation. Tavistock Publs.

Chanlat, J. F., Davel, E., \& Dupuis, J. P. (2013). Crosscultural Management. New York: Routledge.

Davel, E., Dupuis, J. P., \& Chanlat, J. F. (2008). Gestion en contexte interculturel. Montrèal: PUL/TÉLUQ.

Delgado-Márquez, B. L., \& Hurtado-Torres, N. E., \& Bondar, Y. (2011). La internacionalización em la enseñanza superior: invéstigación teórica y empírica sobre su influencia em las clasificaciones de las instituciones universitárias. Revista de Universidad y Sociedad del Conocimiento, 8(4): 101-122.

De Wit, H. (2003). Updating the definition of internationalization. International Higher Education, 33: 2-28.

De Wit, H. (2004). Internationalization remodeled: definition, approaches, and rationales. Journal of Studies in International Education, 8(1): 5-31.

De Wit, H., Jaramillo, I. C., Gacel-Avila, J., \& Knight, J. (2005). Educación Superior em América Latina: la dimensión internacional. Bogotá: Mayol Ed.

FGV - Quem somos - Escola de Administração de Empresas de São Paulo. Disponível em: http://eaesp.fgvsp.br/sobreafgveaesp/mensagem Acesso em: 18/11/2015.

Freitas, M. E. (2005). Executivos brasileiros expatriados na França: uma contribuição aos Estudos Organizacionais Interculturais. Monografia concurso de professor titular da EAESP/FGV. São Paulo - SP.

Freitas, M. E. (2008). O imperativo intercultural na vida e na gestão contemporânea. Organização \& Sociedade, 15(45): 79-89.

Freitas, M. E. (2009). A mobilidade como novo capital simbólico nas organizações ou sejamos nômades? Organização \& Sociedade, 16(49): 247-264.

Global Universities Rankings. Disponível em: http://www.usnews.com.education/bet-globalunviersities/articles/methology. Acesso em: 19/11/2015.
Goulart, S., \& Vieira, M. M. F. (2008). Desenvolvimento e organizações: as universidades como eixo de articulação entre o local e o global. Organização \& Sociedade, 15(45): 91-106.

Jang, J. Y. (2009). Analysis of the relationship between internationalization and the quality of higher education. Minneapolis: University of Minnesota.

Kedia, B. L., \& Englis, P. D. (2011). Internationalizing business education for globally competente managers. Journal of Teaching in International Business, 22: 13-28.

Knigth, J. (1994). Internationalization: elements and checkpoints. Ottawa: Canadien Bureau for Interantional Education (CBIE).

Knight, J. (1997). Internationalization of higher education: a conceptual framework. In: Knight, J., \& De Wit, H. (Orgs.). Internalionalization of higher education in the Asia Pacific countries. Amsterdam: European Association of International education.

Lausaus, S. P. (2012). A internacionalização da educação superior: um estudo de caso da Universidade Federal de Santa Catarina. Tese de doutorado. Salvador: Universidade Federal da Bahia.

Madeira, A. B., \& Silveira, J. A. G. (2013). Internacionalização de empresas. São Paulo: Saint Paul Ed.

Mariotto, F. L. (2007). Estratégia internacional da empresa. São Paulo: Thomson.

Morosini, M. C. (2011). Internacionalização na produção de conhecimento em IES brasileiras: cooperação tradicional e cooperação internacional horizontal. Educação em Revista, 27(1): 93-112.

Motta, F. C. P., \& Vasconcelos, I. G. F. (2002). Teoria Geral da Administração. São Paulo Thomson.

OCDE. (2014). Education at a Glancel OECD Indicators. Paris: França.

Pimenta, R. D. (2006). Internacionalização de escolas de negócios: análise do processo de internacionalização da Fundação Dom Cabral. Belo Horizonte: Pontifícia Universidade Católica.

Reddy, Y, M. (2008). Global accreditation systems in management education: a critical analysis. South Asian Journal of Management, 15(2): 61-80.

Souza, E. P., \& Fleury, M. T. L. (2009). Estratégias e competências para a internacionalização de 
instituições de ensino superior do Brasil. Anais... XXXIII Encontro da ANPAD, São Paulo - SP.

Stallivieri, L. (2004). Estratégias de internacionalização das universidades brasileiras. Caxias do Sul: Educs.

Stewart, T. A. (1998). Capital intelectual. Rio de Janeiro: Campus.

Stiglitz, J. E. (2003). Os exuberantes anos 90. São Paulo: Companhia das Letras.

Stiglitz, J. E. (2006). Un autre monde. Paris: Fayard.

Taylor, J. (2004). Toward a strategy for internationalization: lessons and pratice from four universities. Journal of Studies in International Education, 8(2): 149-171.

Thomson Reuters. Academic Reputation Survey 2014 Report of Findings. Disponível em: http://science.thomsonreuters.com/globalprofilespro ject/gpp-reputational/ Acesso em: 19/11/2015.

Van Der Wende, C. (1999). Quality assurance of internationalization and Internationalization of quality assurance. In: J. Knight \& H. De WIT (Eds.). Quality and internationalization in higher education. Paris: OECD,

Van Der Wende, C. (2001). Internationalization policies: about new trends and contrasting paradigms. Higher Education Policy, 14: 249-259.

Warwick, P. (2014). The international business of higher education - a managerial perspective on the internationalization of $\mathrm{UK}$ universities. The International Journal of Management Education, 12(2): 91-103.

Weick, K. (1976). Educational organizations as loosely coupled systems. Administrative Science Quarterly, 21: 1-19. 